\title{
Charge Neutralization in Nickel Coated Simulated High Level Waste Glass Analyzed by Secondary Ion Mass Spectrometry
}

\author{
V Karki ${ }^{1^{*}}$, D Bhattacharya ${ }^{2}$, M Singh ${ }^{1}$ \\ ${ }^{1}$ Fuel Chemistry Division, Bhabha Atomic Research Centre, Mumbai, 400 085, India \\ ${ }^{2}$ Solid State Physics Division, Bhabha Atomic Research Centre, Mumbai 400 085, India
}

Received:17 August, 2017; Accepted: 18 December, 2017; Published: 26 March, 2018

*Corresponding author: V Karki, Fuel Chemistry Division, Bhabha Atomic Research Centre, Mumbai, India, E-mail: vijaykarki.karki@gmail.com

\begin{abstract}
Secondary ion mass spectrometer (SIMS) analysis of insulator samples suffers from charge build up problems. Most widely used method for charge neutralization using SIMS is to coat the sample with a precious metal like $\mathrm{Au}, \mathrm{Pt}$ or Pd and operating SIMS in negative secondary ion detection mode in conjunction with Normal incidence Electron Gun (NEG). For routine sample analysis, in order to investigate the surface, depth and spatial distribution of elements and molecules in the sample to study various phenomena (corrosion, diffusion, precipitate formation, grain boundary diffusion etc.), this method is less economical because of the use of precious metal in coating the sample. In the present work, a novel method for charge neutralization has been investigated by using $\mathrm{Ni}$ coating instead of $\mathrm{Au}, \mathrm{Pd}$ or Pt on simulated HLW (High Level Liquid Waste) glass sample and carrying out SIMS analysis. Overlapping of normalized energy distribution curves for the elemental ions $\mathrm{Ni}$ - and $\mathrm{Fe}$ - in the $\mathrm{Ni}$ film (conductive) and HLW glass (non-conductive) respectively, confirmed that effective charge neutralization was obtained in the Ni coated sample. Surface, depth and 3D (3-Dimensional) distribution analyses of elements were also carried out after pre-sputtering the $\mathrm{Ni}$ film deposited on the sample which revealed uniform spatial distribution of all the elements in the HLW sample.
\end{abstract}

\section{Introduction}

Nuclear Power Programme in India is based on "closed fuel cycle". Closed fuel cycle involves reprocessing and recycling of spent nuclear fuel coming out of nuclear reactors. These processes are associated with production of HLW. Composition of generated HLW depends on various factors which include fuel nature, its history in the reactor and the reprocessing chemistry. One of the most crucial aspects of nuclear power generation for any country is the treatment and disposal of generated radioactive nuclear waste. Management of HLW in India has been carried out by implementing three step strategy involving immobilization, interim storage followed by ultimate disposal. Immobilization of HLW in suitable glass matrix has been more widely adopted in comparison to other matrices (e.g. hydroxy, synroc, apatite, ceramic, etc.), due to numerous advantages offered by glass matrix such as optimal waste loading, adequate leach resistance and long term stability of the vitrified waste product [1-3]. Belonging to these categories of glasses, borosilicate glass is the most popular choice for vitrification since it possesses the desirable properties required for allowing long term storage of the radioactive waste and hence providing containment for isolation of radioactivity from the environment.

Extensive research and development efforts have finally culminated into design and construction of India's first vitrification facility at Waste Immobilisation Plant (WIP), Tarapur. The second vitrification facility to manage HLW generated during reprocessing of spent nuclear fuel from various research reactors was commissioned at Bhabha Atomic Research Centre (BARC), Trombay [4]. As a practice, a detailed investigation and evaluation of vitrified waste product is carried out during inactive vitrification runs with simulated waste. Various properties of the conditioned products such as product melt temperature, homogeneity, waste loading, thermal stability, radiation stability and chemical durability are evaluated using advanced analytical instruments, e.g. Scanning Electron Microscope (SEM), X-ray Diffraction (XRD), Electron Microprobe Analyzer (EPMA), Inductively Coupled Plasma Spectrometer, Thermal analysis system etc..

In order to understand the structural modifications in the three dimensional network of incorporation of waste constituents in glass matrix, a series of detailed characterization studies are necessarily important. Similarly, to ascertain the quality of the vitrified waste product with respect to product acceptance criteria, qualitative and quantitative characterization of vitrified waste product for major and minor constituents is also critical. Elemental characterization of Power Reactor Thoria Reprocessing Facility (PRTRF) simulated waste glass has been already carried out by our research group using Laser Induced Breakdown Spectroscopy (LIBS) technique implementing multivariate approach under optimized experimental conditions [5].

Surface analysis techniques play an important role in understanding the long term corrosion behaviour of high level radioactive vitrified waste under repository conditions. Investigation of surface microstructure and depth distribution of elements provides a vast amount of information in order to 
understand the corrosion mechanism in borosilicate glasses which are intimately tied to the ability to safely store the vitrified material in a deep geological repository [6]. Several surface analysis techniques which are being routinely used to characterize glass include SIMS, Fourier Transform Infrared Reflection Spectroscopy (FT-IRRS), Auger Electron Spectroscopy coupled with Ion Milling (AES-IM) and Scanning Electron Microscopy coupled with Energy Dispersive Spectroscopy (SEM-EDS) [610]. In all of the above mentioned techniques, particularly SIMS has proved to be a convenient and rewarding technique for the chemical characterisation and corrosion studies of glasses due to its high sensitivity and unmatched depth resolution [6,9,11-14].

The working principle of SIMS is based on bombarding the sample surface with energetic primary ions and collecting the ejected secondary ions with a suitable mass spectrometer [7]. Consequently, analyses of insulator samples create problems due to charge build up on the analysis region. The effective charge build up on the analysis region depends on the intensity of incoming primary charged ions and sputtered secondary electrons and ions $[7,8]$. Such charging affects primary as well as secondary ion trajectories which ultimately leads to instability, reduction, or even complete suppression of the secondary ion currents $[7,8,15,16]$. Charging effects also promote field enhanced migration of the mobile ions in the solid insulator samples, thereby leading to erroneous depth profiles [7]. Because of the various advantages offered by SIMS technique, numerous methods for charge build up compensation in insulators have been developed in the last few decades $[7,8]$. In comparison to all the charge compensation techniques, electron bombardment in conjunction with a conductive layer of $\mathrm{Au}, \mathrm{Pt}$ or Pd remains to be the most successful and most extensively employed approach for maintaining charge balance during SIMS analysis. Even with the NEG, which can generate an electron beam that is easy to focus on primary beam raster area, it has often been necessary to coat the sample with a conductive film, such as $\mathrm{Au}, \mathrm{Pt}$ and Pd [15]. Although this technique is highly efficient, the use of noble metals makes it less economical especially for routine sample analysis which is required for regular monitoring of HLW glasses and hence an alternative approach to the problem is required.

In the present work, a novel approach for charge neutralization has been presented, by replacing the noble metals $\mathrm{Au}, \mathrm{Pt}$ and Pd used in the conductive coating of HLW glasses with $\mathrm{Ni}$ and operating SIMS in negative secondary ion beam mode in conjunction with NEG.

\section{Experimental}

\section{Sample Preparation}

The sample 'G10' used in the present study was a vitrified simulated PRTRF generated nuclear waste glass. The synthetic standard sample was prepared in the laboratory with simulated compositions. Glass formation chemicals $\mathrm{SiO}_{2}, \mathrm{H}_{3} \mathrm{BO}_{3}, \mathrm{Na}_{2} \mathrm{CO}_{3}$, $\mathrm{BaCO}_{3}$, and $\mathrm{TiO}_{2}$ were used to form barium borosilicate glass with a base composition of $\left(\mathrm{SiO}_{2}\right)_{0.44}\left(\mathrm{~B}_{2} \mathrm{O}_{3}\right)_{0.26}\left(\mathrm{Na}_{2} \mathrm{O}\right)_{0.16}(\mathrm{BaO})_{0.13}$ $\left(\mathrm{TiO}_{2}\right)_{0.01}$ including specified amounts of waste oxides. Table 1 shows the composition of the major and minor constituents present in glass 'G10' measured using ICP-AES technique. The glass preparation procedure has been discussed elsewhere [17].

Table: 1 Composition of simulated HLW glass sample 'G10' prepared and used in the present study.

\begin{tabular}{|c|c|c|c|c|c|c|c|c|c|}
\hline & \multicolumn{9}{|c|}{ Elemental concentration (wt\%) } \\
\hline Sample & $\mathrm{Na}$ & $\mathrm{Th}$ & $\mathrm{Cs}$ & $\mathrm{Sr}$ & $\mathrm{Fe}$ & $\mathrm{Cr}$ & $\mathrm{Ni}$ & $\mathrm{F}$ & $\mathrm{Al}$ \\
\hline $\mathrm{G} 10$ & 12.2 & 0.9 & 0.5 & 0.004 & 3.5 & 0.1 & 0.1 \\
\hline
\end{tabular}

Deposition of Ni Film on HLW Glass using Magnetron secondary ion detection mode in conjunction with NEG. The Sputtering System

Thin film of Ni on HLW glass sample 'G10' was deposited using magnetron sputtering system. Ni target used for coating the HLW glass sample had a high purity of $\sim 99.95 \%$ and was presputtered before deposition on HLW glass. HLW glass substrate was held at a distance of $74 \mathrm{~mm}$ from the target and was rotated at $4 \mathrm{rpm}$ to ensure uniform deposition of the $\mathrm{Ni}$ film on the glass surface. The background Ar gas flow was maintained to $20 \mathrm{sccm}$ using a digital mass flow controller. The working vacuum with flow of Ar gas was $\sim 6 \times 10^{-3}$ mbar during deposition. DC power supplied to Ni target was maintained at 80 watts. Deposition time of Ni film on glass substrate was $10 \mathrm{~min}$.

\section{Sims Analysis}

The surface, depth and 3D distribution analyses of elements in Ni coated 'G10' sample was investigated by using magnetic sector Cameca IMS-7f instrument equipped with both oxygen $\left(\mathrm{O}_{2}{ }^{+}\right.$and $\left.\mathrm{O}^{-}\right)$and cesium $\left(\mathrm{Cs}^{+}\right)$primary ion beams. All the analyses were carried out using $\mathrm{Cs}^{+}$primary ion beam with negative sample was placed at a potential of $-5 \mathrm{KV}$ and the electrons were accelerated with energy of $5 \mathrm{KeV}$. In this configuration, electron beam forms a cloud of electrons near the sample surface. During the analysis, positive charge build up on the sample surface due to incoming primary $\mathrm{Cs}^{+}$ions and ejected secondary ions and electrons, was neutralized by the exact amount of electrons taken from the electron cloud. The detailed working principle of charge compensation using NEG in this configuration is described elsewhere [18]. Surface, depth and 3D distribution analyses of elements were carried out after pre-sputtering the Ni coating on the glass sample. Depth distribution analyses were carried out at a beam current of $35 \mathrm{nA}$. Primary beam was raster over an area of $150 \mu \mathrm{m} \times 150 \mu \mathrm{m}$ and secondary ions were collected over an analysis region of $42 \mu \mathrm{m}$ in diameter at the centre of raster area in order to remove the crater edge effects. Surface and 3D distribution analysis were carried out with beam current of $2 \mathrm{nA}$ and the sputtered secondary ions were collected from an analysis area of $150 \mu \mathrm{m} \times 150 \mu \mathrm{m}$ using high resolution electron multiplier detector having maximum pixel density of $1024 \times 1024$. 


\section{Results and Discussions}

\section{Ni Coating}

Figure. 1(a) and (b) represents the optical images of the HLW sample 'G10' acquired by the optical camera located above the sample in the analysis chamber. The figure represents two different locations on the sample surface under different analysis conditions. The square region represents the primary beam raster area of dimension $150 \mu \mathrm{m} \times 150 \mu \mathrm{m}$. figure 1 (a) shows the analysis condition in which the electron beam is switch on after the primary beam. The zigzag black lines near the analysis region are due to the arcing effects produced by charge build up on the analysis region. figure 1 (b) represents the condition in which NEG is made active before the primary beam. In this configuration, no arcing effects were observed due to the complete neutralization of the surface charge. The area covered by the electron beam is greater than the primary beam raster area as shown by the contrast in the light colour observed in the region near the analysis area shown in figure $1(\mathrm{~b})$.

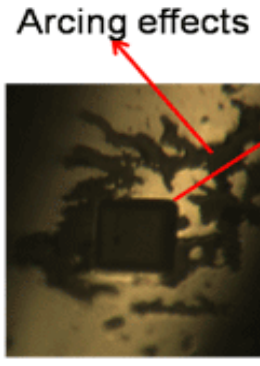

(a)

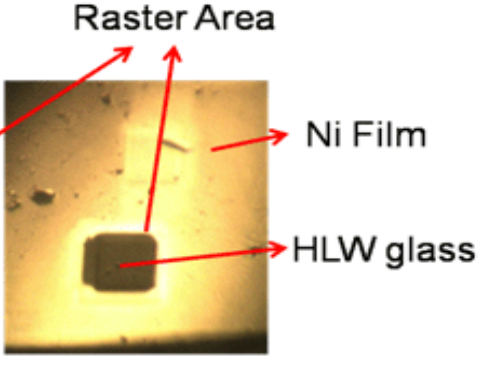

(b)
Figure 1:Optical images acquired by the camera located above the $\mathrm{Ni}$ coated HLW glass sample 'G10' showing two different analysis conditions (a) NEG started after primary ion beam and (b) NEG started before primary ion beam. The square region represents the primary beam raster area of $150 \mu \mathrm{m} \times 150 \mu \mathrm{m}$.

For accurate analysis of insulator samples using SIMS, it is essential to ensure that the conductive coating on the sample is homogenous w.r.t. depth and on surface. figure 2 represents the depth distribution of $\mathrm{Ni}$ in $\mathrm{Ni}$ thin film, deposited on the surface of HLW glass. As evident from the figure, $\mathrm{Ni}$ is homogenously distributed with respect to depth. It was observed that at the end of the film or Ni-glass (metal-insulator) interface, the depth distribution curve of Ni showed erroneous behaviour (not shown in the figure 2). The erroneous depth profile of $\mathrm{Ni}$ in the interface region may be due to non uniform charge compensation in different matrices which was also observed by Gerhard Bart et al in case of surface analysis of leached radioactive glass surface [9].

\section{Energy Distribution Spectra of Elements in Ni Film and HLW Glass}

The change in the energy distribution spectrum of sputtered secondary ions represents the change in the work function of analysis surface. In other words, it also represents the change in the surface potential of the sample surface. In case for the analysis of insulator samples, if charge neutralization is not efficient, the energy distribution spectrum of secondary ions in insulator sample will be different in comparison to the conductive sample. It was noticed that scanning the sample potential for an insulator would destroy the charge neutralization adjustment by modifying the electron beam energy, so the energy distribution spectrum of secondary ions were measured by increment in the potential of electrostatic analyzer in step of 1 Volt with a bandpass of a $2 \mathrm{eV}$ over the instrumental energy window. figure 3 represents the normalized energy distribution patterns of $\mathrm{Ni}^{-}$and $\mathrm{Fe}^{-}$secondary ions acquired from $\mathrm{Ni}$ film and HLW glass sample respectively. As it is evident from the figure that the energy distribution patterns for both are similar and overlapping, which confirms that surface charge neutralization is effective in this configuration.

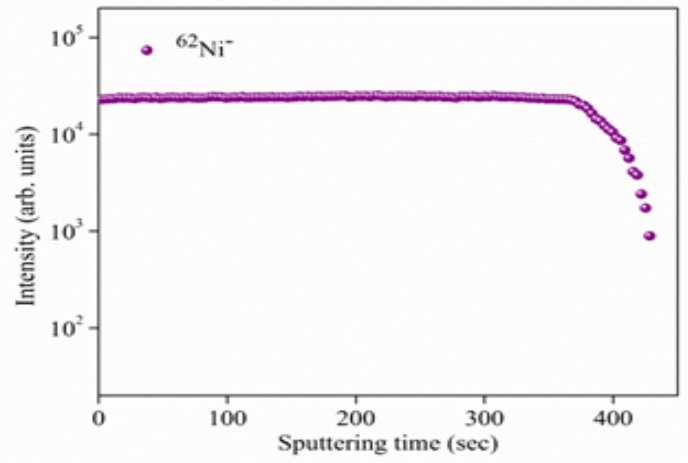

Figure 2:SIMS depth profile of $\mathrm{Ni}^{-}$in Ni coated HLW glass. Primary ion beam: $\mathrm{Cs}^{+}$, Secondary ion: ${ }^{62} \mathrm{Ni}$

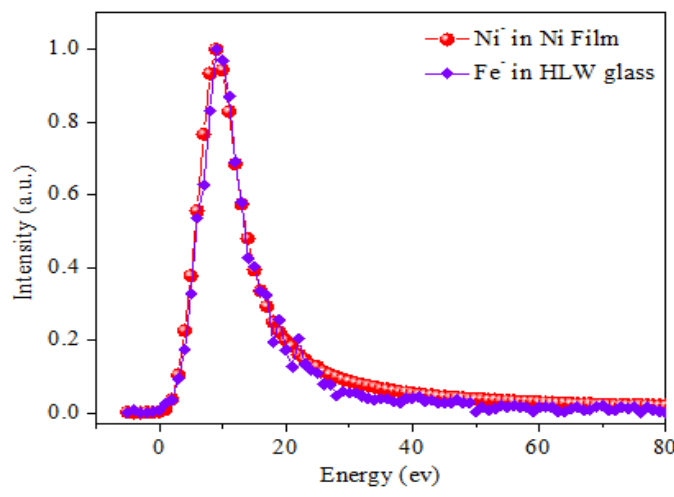

Figure 3:Normalized secondary ion energy distribution of $\mathrm{Ni}^{-}$and $\mathrm{Fe}^{-}$ collected from Ni thin film and HLW glass sample.

\section{Surface Analysis}

After pre sputtering the deposited $\mathrm{Ni}$ film, the surface distribution studies of the elements was carried out in the HLW glass sample. The surface distribution of different elements are shown in figure. 4 (a), (b), (c), (d), (e), (f), (g), (h) and (i) for F, Na, $\mathrm{Al}, \mathrm{Cr}, \mathrm{Fe}, \mathrm{Ni}, \mathrm{Sr}, \mathrm{Cs}$ and $\mathrm{Th}$ respectively. The surface distribution studies revealed that the elements are homogenously distributed laterally. The uniform surface distribution images also confirms that the charge neutralization is effective in Ni coated HLW glass in conjunction with NEG. 


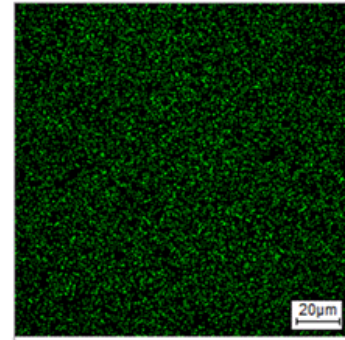

(a)

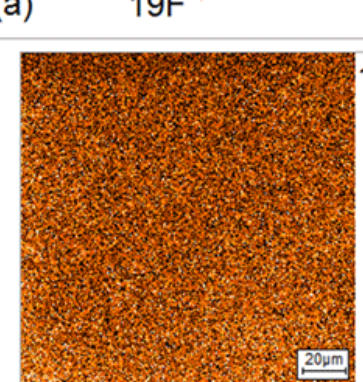

(d) $\quad 52 \mathrm{Cr}$

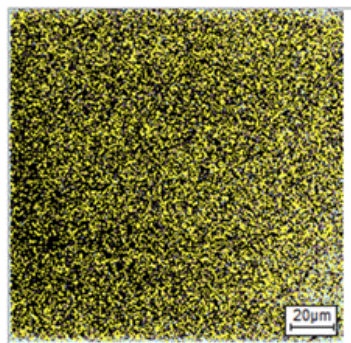

(g)

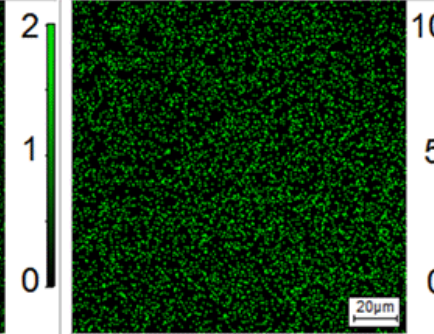

(b)

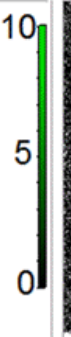

(c)

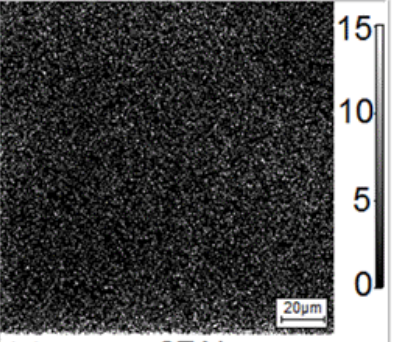

$27 \mathrm{Al}$

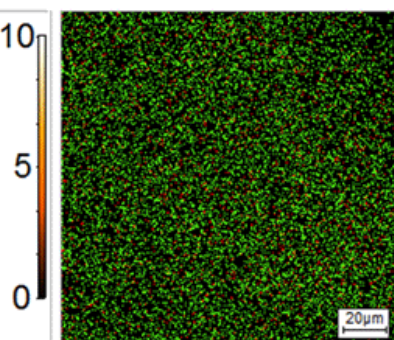

(e)

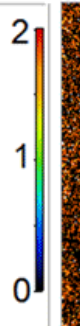

(f)

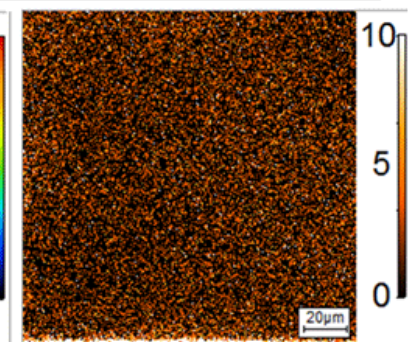

$58 \mathrm{Ni}$

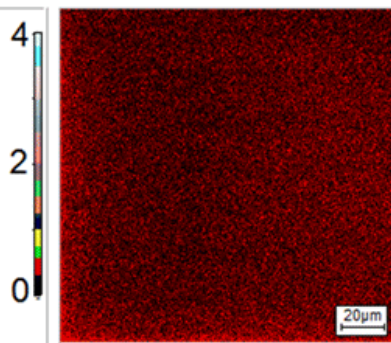

(h) $\quad 133 \mathrm{Cs}$
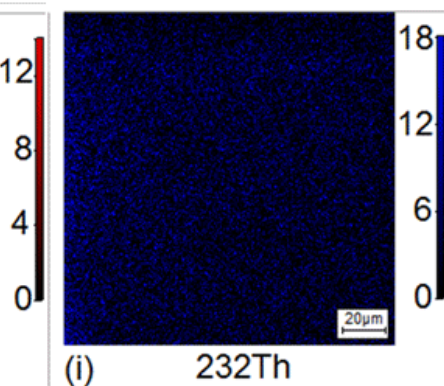

Figure 4:Surface distributions of (a) ${ }^{19} \mathrm{~F}-$, (b) ${ }^{23} \mathrm{Na}-$, (c) ${ }^{27} \mathrm{Al}-$, (d) ${ }^{52} \mathrm{Cr}-$, (e) ${ }^{56} \mathrm{Fe}-$, (f) ${ }^{58} \mathrm{Ni}-$, (g) ${ }^{88} \mathrm{Sr}-$, (h) ${ }^{133} \mathrm{Cs}$-, (i) ${ }^{232} \mathrm{Th}$ - in Ni coated 'G10' HLW glass sample. The square region for each element represents the primary beam raster area of $150 \mu \mathrm{m} \times 150 \mu \mathrm{m}$. The color on each pixel corresponds to the counts as shown by the color bar on the right side of the image.

\section{Depth Analysis}

The depth distribution curves for different elements $\mathrm{F}, \mathrm{Na}, \mathrm{Al}$, $\mathrm{Cr}, \mathrm{Fe}, \mathrm{Ni}, \mathrm{Sr}, \mathrm{Cs}$ and $\mathrm{Th}$ are shown in figure 5. It is evident from the figure that all the elements are uniformly distributed with respect to depth. The uniform depth distribution curve also revealed that the charge compensation is also achievable by using Ni coated HLW glass in conjunction with NEG.

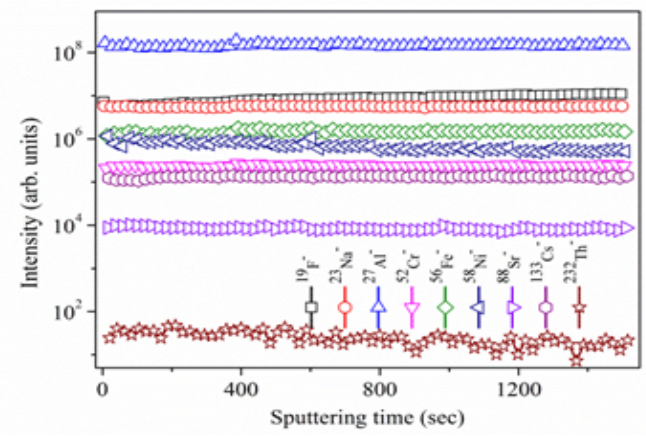

Figure 5:OSIMS depth profiles of ${ }^{19} \mathrm{~F}-,{ }^{23} \mathrm{Na}-,{ }^{27} \mathrm{Al}-,{ }^{52} \mathrm{Cr}-,{ }^{56} \mathrm{Fe}-,{ }^{58} \mathrm{Ni}-, 88 \mathrm{Sr}-$ ,${ }^{133} \mathrm{Cs}-$ and ${ }^{232} \mathrm{Th}$ - in Ni coated HLW glass sample 'G10'
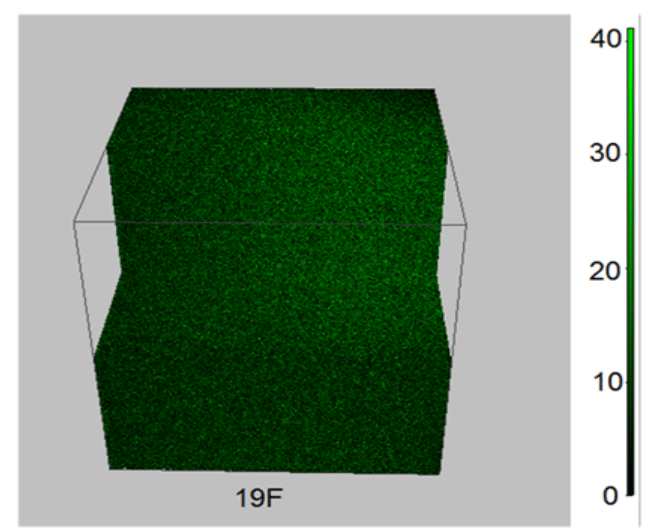

Figure 6:3D distributions of 19F- in Ni coated HLW glass sample. Composite mode of 3D image representation was chosen. Measurement parameters: primary ion beam, $\mathrm{Cs}^{+}$; monitored secondary ions polarity, negative ( ${ }^{19} \mathrm{~F}-$ ); raster area, $150 \mu \mathrm{m} \times 150 \mu \mathrm{m}$; measured cycles, 128 ; image size, $128 \times 128$ pixels. The image has been showed as a cut-out to represent the depth structure. The color bar shown in the right side of each image represents the intensity on each pixel. 


\section{D Distribution Analysis}

In order to study the spatial distribution of different elements in the HLW sample, 3D distribution analysis were also carried out using SIMS. figure 6 represent 3D distribution of 19F- in the sample. It can be interpreted from the figure that the element 19F- is uniformly distributed spatially. The uniform distribution of $19 \mathrm{~F}$ - in the sample also represents that the charge build up was effectively neutralized in the Ni coated sample. Similar distribution curves were also observed for $\mathrm{Na}, \mathrm{Al}, \mathrm{Cl}, \mathrm{Cr}, \mathrm{Fe}, \mathrm{Ni}, \mathrm{Sr}$, $\mathrm{Ru}$ Cs and Th.

\section{Summary and Conclusions}

A new novel method for charge neutralization during SIMS analysis of insulator samples especially glass has been presented. In this method, Ni coating in place of precious metals coating like $\mathrm{Au}, \mathrm{Pt}$ and Pd was used in conjunction with NEG. The coincidence of normalized energy distribution spectra of secondary ions in Ni film and HLW glass confirmed effective charge neutralization on the sample analysis region. Surface, depth and 3D analyses of elements were also carried out on simulated Ni coated HLW glass under the same experimental conditions. These analyses also revealed that effective charge neutralization is achievable using $\mathrm{Ni}$ coating in conjunction with NEG.

\section{Acknowledgments}

The authors are thankful to Dr. Arnab Sarkar, Dr. P.G. Jaison, Dr. S. Kannan, Head, Fuel Chemistry Division, Prof. B.S. Tomar, Director, Radiochemistry and Isotope Group and Prof. Saibal Basu, Head, Solid State Physics Division, B.A.R.C. for their constant support and encouragement in SIMS work.

\section{References}

1. O K Karlina, A V Ovchinnikov, M I Ozhovan. Immobilization of sulfatecontaining wastes in borosilicate glass using fluoride additives. Atomic Energy. 1994;76(3):236-239. Doi:org/10.1007/BF02408200

2. L L Hench, D E Clark, J Campbell. High level waste immobilization forms. Nucl Chem Waste Manage. 1984;5(2):149-173. Doi:org/10.1016/0191-815X(84)90045-7

3. A J Freeman, G H Lander. Handbook on the physics and chemistry of the actinides. Elsevier. 1987.

4. N S Sunder Rajan, P D Ozarde. Natural air cooling for interim storage for solidified highly radioactive wastes, Proc. Indo-Soviet Seminar on Radioactive Waste management. Moscow. 1980.

5. M Singh, V Karki, R K Mishra, A Kumar, C P Kaushik, X Mao, et al. Analytical spectral dependent partial least squares regression: a study of nuclear waste glass from thorium based fuel using LIBS. J Anal At Spectrom. 2015;12:2507-2515. Doi:10.1039/C5JA00372E
6. J J Neeway, S Kerisit, S Gin, Z Wang, Z Zhu, J V Ryan. Low-temperature lithium diffusion in simulated high-level boroaluminosilicate nuclear waste glasses. J Non-Cryst Solids. 2014;405:83-90. doi:org/10.1016/j. jnoncrysol.2014.08.053

7. H W Werner, A E Morgan. Charging of insulators by ion bombardment and its minimization for secondary ion mass spectrometry (SIMS) measurements. J Appl Phys. 1976;47(4):1232-1242. Doi:org/10.1063/1.322845

8. A D Appelhans, D A Dahl, J E Delmore. Neutralization of sample charging in secondary ion masss via a pulsed extraction field. Anal Chem. 1990;62(15):1679-1686. Doi:10.1021/ac00214a030

9. G Bart, E T Aerne, H U Zwicky. Experience in SIMS surface analysis of radioactive waste glasses. Nucl Instrum Methods Phys Res Sect B. 1986;17(2):127-136. Doi: org/10.1016/0168-583X(86)90074-1

10. J Lorinčík, D Veselá, S Vytykáčová, B Švecová, $P$ Nekvindová, A Macková, et al. Comparison of SIMS and RBS for depth profiling of silica glasses implanted with metal ions. J Vac Sci Technol B. 2016;34(3):03H1291-03H129-4. Doi:org/10.1116/1.4944525

11. C T Lee, D E Clark. Characterization of glass surfaces. Appl Surf Sci. 1985;20(4):397-412. Doi:org/10.1016/0378-5963(85)90164-3

12. $M D$ Bardi, H Hutter, $M$ Schreiner. ToF-SIMS analysis for leaching studies of potash-lime-silica glass. Appl Surf Sci. 2013;282:195-201. Doi:org/10.1016/j.apsusc.2013.05.101

13. Y Dubowski, A L Sumner, E J Menke, D J Gaspar, J T Newberg, R C Hoffman, et al. Interactions of gaseous nitric acid with surfaces of environmental interest. Phys Chem Chem Phys. 2004;14:3879-3888. Doi:10.1039/B404127E

14. A Lodding, $P$ V Iseghem. In-depth distribution of elements in leached layers on two HLW waste glasses after burial in clay; step scan in SIMS. J Nucl Mater. 2001;298(1-2):197-202. Doi:org/10.1016/S00223115(01)00620-1

15. J M McKinley, F A Stevie, $C N$ Granger, $D$ Renard. Analysis of alkali elements in insulators using a CAMECA IMS-6f. J Vac Sci Technol A. 2000;18:273-277. Doi:org/10.1116/1.582146

16. C P Hunt, C T H Stoddart, M P Seah. The surface analysis of insulators by SIMS: charge neutralization and stabilization of the surface potential. Surf Interface Anal. 1981;3(4):157-160. Doi:10.1002/sia.740030404

17. A Sarkar, R K Mishra, C P Kaushik, P K Wattal, D Alamelu, S K Aggarwal. Analysis of barium borosilicate glass matrix for uranium determination by using ns-IR-LIBS in air and $\mathrm{Ar}$ atmosphere. Radiochim Acta. 2014;102(9):805-812. Doi:org/10.1515/ract-2014-2243

18. H N Migeon, M Schuhmacher, G Slodzian. Analysis of insulating specimens with the Cameca IMS4f. Surf Interface Anal. 1990;16(112):9-13. Doi:10.1002/sia.740160105 